\title{
The labor of intestinal fence in inflammatory bowel disease
}

\begin{abstract}
Grave antagonistic effects can happen in the dearth of an efficient intestinal mucosal barrier, as this is perilous for shield against invading microorganisms. In inflammatory bowel diseases Crohn's disease and ulcerative colitis, the intestinal barrier function is defective due to defective production of antimicrobial peptides, alterations of the mucus layer and defects in the process of autophagy. This article reviews the disturbances in the components of healthy intestinal mucosal barrier in inflammatory bowel disease. This ailment involves chronic inflammation of the digestive tract and sometimes leads to life-threatening complications.
\end{abstract}

Volume 5 Issue 5 - 2018

\begin{abstract}
Jes Paul
Department of molecular and cellular physiology, Albany Medical College, USA

Correspondence: Jes Paul, Research Associate, Department of molecular and cellular physiology, Albany Medical College, 43 New Scotland Ave, Albany, NY 12208, USA, Tel + 14049802103 , ORCID ID: 0000-0002-0258-720X, Email jesrejoice@gmail.com
\end{abstract}

Received: August 30, 2018 | Published: September 25, 2018

\section{Introduction}

The intestinal tract is summoned with many multifarious and arduous task like digestion and nutrient absorption. The host has to provide a serene coexistence with this divergent microbial community, as the gut lumen cherish an huge number of microorganisms. Appropriate detection and expulsion of pathogenic microorganisms is a way of avoidance along with prevention of an inordinate immune response against commensals. ${ }^{1-4}$ The intestinal mucosa is supplied with diverse specific and unspecific safeguarding mechanisms that unitedly build a obscure and effectual mucosal barrier, in order to thinder a injurious adhesion and encouragement of microorganisms. ${ }^{5,6}$ The symptoms of this disease are manifested as Diarrhoea, Fever and fatigue, Abdominal pain and cramping, Blood in your stool, reduced appetite and Unintended weight loss.

\section{Machineries of the intestinal mucosal barrier}

\section{The epithelium}

An able physical borderline between luminal contents and the body's interior. ${ }^{2,4}$ The intestinal epithelium comprise micro fold-cells that are part of the follicle-associated epithelium and accountable for the carrying of luminal bacteria and antigens to subjacent immune cells. ${ }^{4,5}$ A picky permeable barrier is formed by intestinal epithelium because it grant the passage of water, electrolytes and dietary nutrients but forbids a detrimental attack of foreign antigens, microorganisms and their toxins.

To satisfy this dare, intestinal epithelial cells are attentively allied by diverse protein complexes comprising tight junctions, adherent's junctions and desmosomes. These cell-cell links equalize the mechanical cohesion of the cells, and are also rudimentary for the govern of the paracellular permeability. Epithelial homeostasis and equilibrium for an effective intestinal barrier is sustained by the equipoise of cell proliferation and epithelial apoptosis. Significant regulators of this homeostasis via signalling pathways are the transforming growth factor (TGF)- $\alpha$, provocative proliferation, and TGF- $\beta$ inhibiting cell development via signalling pathways.

Concerning the identification of microbes and the commencement of appropriate immune responses of peculiar importance are so called pattern-recognition receptors (PRRs) that are declared by different cell types within the gastrointestinal tract including epithelial cells and immune cells. Habitually, PRRs recognize microorganisms by maintained structural motifs that are typical for them, like lipopolysaccharide, peptidoglycan, bacterial DNA and flagellin. ${ }^{4,6,7}$

\section{Antimicrobial peptides (AMP), an intact side of innate immunity}

AMPs portrays two families in mammals i.e defensins and the cathelicidins. ${ }^{8,9}$ The members of both subfamilies manifest a wide scale of antimicrobial activity. ${ }^{10}$ Apart from AMPs, antimicrobial effects have been imputed to diverse proteins with other elegant roles. To say a few, microbicidal actions are related for the families histones and ribosomal proteins as well as for ubiquitin. ${ }^{11-14}$

\section{The sticky intestinal mucus layer}

A layer that overcoats the mucosa as a sticky gel and contribute aegis counter to attacking microbes as well as other deleterious insults from the intestinal lumen, inclusive of mechanical bruises or noxious enzymes. Apart from its safeguarding role, mucus also has a lubricating caliber which is vital to keep the mucosal surface hydrated..$^{15}$ The secretory gel-generating mucins are requisite for the construction of an perfect and durable mucus layer. Mucins are filledin with numerous sulfate and silica acid residues ${ }^{16,17}$ in specific doses and these proffer the mucins extra shelter against bacterial assault and enzymatic decadence. ${ }^{18-20}$

The mucus layer acts not only as a physical hindrance but also feature antimicrobial character. Moreover numerous AMPs were recognized in mucus extracts. Additionally antimicrobial peptides, mucus also comprise of secretory IgA that is translocated beyond the epithelium in big volumes and aid to hinder an assault of luminal microorganisms. ${ }^{15,21}$

\section{Intestinal barrier and intestinal bowel disease}

Imperfections in the intestinal epithelial barrier role are a peculiar attributes of IBD. The tumult can influence various levels of the preventative mechanisms, inclusive of mutations of PRRs, unbalanced AMP production, a faulty mucus layer, amendments in autophagy or an added on epithelial barrier permeability, and account to an 
inadequate shield over microbial fidelity and invasion. The ensuing asymmetry between the microbes and the safeguarding host-defense techniques let more bacteria to be in straight connection with the epithelium and mucosal immune processes. Accordingly, redeeming immune reactions are overly elicited and eventually end in chronic intestinal inflammation.

IBD chiefly touch the most densely colonized gut segments, namely the distal ileum and colon, an connection of the microbial flora in the pathogenesis of the ailment is obvious. Likewise, various animal models exposed the pivotal assistance of microbes to the advancement of inflammation. ${ }^{22,23}$ Till now, despite of broad research, no precise IBD-causing pathogen could be recognized. ${ }^{24,25}$

But in disease pathogenesis, the intestinal microbial community seems to be pressingly entailed. ${ }^{26}$ Researches exhibiting a notable rise in surface related bacteria and to intracellular bacteria in patients with IBD. This intricate a scarcity in the preventive mechanisms that capably hold afar microbes from the epithelial surface in the healthy intestine. Autophagy plays multiple vital roles in IBD pathogenesis by varying techniques inclusive of killing of intracellular bacterial, Paneth cells secrete antimicrobial peptide, goblet cell function is hindered, macrophages produces proinflammatory cytokine, dendritic cells antigen, also in enterocytes there is the endoplasmic reticulum stress response .The process Autophagy is a deterioration process substantial for cellular evenness and balance that allots the cell to salvage cellular components by giving organelles and cytosolic macromolecules to lysosomes. The method is triggered in response to conditions of cellular stress like famishment and growth factor loss. Not only that, the autophagy system is also essential in the antibacterial host-defense as it is tangled in the debasement of invading bacteria. ${ }^{27-29}$ Lately a study showed flaw in the process of autophagy along with an amplified chance to develop the infection. ${ }^{30}$

Fluctuations of the intestinal mucus layer related to its depth, constancy and constitution along with the mucin-structure have been recorded in IBD patients. These transitions are thought to resentfully influence the protective effects of the gel layer and thence might induce an elevated exposure of the epithelium to bacterial irruption.

\section{Epithelial porousness}

Inflated intestinal penetrability has been reported as a poser for IBD steering to the development of inflammation. ${ }^{31}$ In addition to that, raised porousness is allied to a peaked risk of ailment. Many recent studies suggest that the permeability gain forego pathologically blatant inflammation.

Also epithelial apoptosis results in prolonged epithelial permeability. Several studies showcased that in inflammatory bowel disease apoptosis is upregulated. In short, epithelial permeability upsets occur in IBD patients but further researches are necessary to multiply the knowledge about the rudimentary molecular processes also to clear whether these variations play a pivotal function in the pathogenesis.

\section{Conclusion}

The robust intestinal mucosa is ably guarded against pernicious impulse from the gut lumen by a complex and multilayered defense barrier. In the recent times, it became ostensible that the intestinal barrier is imperiled in IBD patients. These barrier agitations include switches of the mucus layer, a unsound AMP genesis, irresolute ER- stress, imperfections in the process of autophagy, raised epithelial retentiveness and all these eventually accounting for an poor protection of the epithelium against attachment and incursion of luminal bacteria. At last, erratic huge amount of microorganisms are permitted to be in direct adjunction with the hosts immune machineries and this is thought to commence a process chronic intestinal inflammation ultimately. Forthcoming studies are needed to encourage detailed mechanisms hidden in the pathogenesis of IBD, to spell out their intricate meshing and to sanction the development of novel remedial advance for the handling of IBD.

\section{Acknowledgements}

None.

\section{Conflict of interest}

The author declares there is no conflict of interest.

\section{References}

1. Wehkamp J, Stange EF. Paneth's disease. J Crowns Colitis. 2010;4(5):523531.

2. Wells JM, Rossi O, Meijerink M, et al. Epithelial crosstalk at the microbiota-mucosal interface. Proc Natl Acad Sci USA. 2011;108 Suppl $1: 4607-4614$

3. Goto Y, Kiyono H. Epithelial barrier: an interface for the crosscommunication between gut flora and immune system. Immunol Rev. 2012;245(1):147-163.

4. Hindryckx P, Laukens D. Intestinal barrier dysfunction: The primary driver of IBD? In: Sami Karoui, editor. Inflammatory Bowel Disease -Advances in Pathogenesis and Management. Rijeka, Croatia: InTech; 2012:23-40.

5. Gill N, Wlodarska M, Finlay BB. Roadblocks in the gut: barriers to enteric infection. Cell Microbiol. 2011;13(5):660-669.

6. Salim SY, Söderholm JD. Importance of disrupted intestinal barrier in inflammatory bowel diseases. Inflamm Bowel Dis. 2011;17(1):362-381.

7. Cario E. Bacterial interactions with cells of the intestinal mucosa: Tolllike receptors and NOD2. Gut. 2005;54(8):1182-1193.

8. Metz-Boutigue MH, Shooshtarizadeh P, Prevost G, et al. Antimicrobial peptides present in mammalian skin and gut are multifunctional defence molecules. Curr Pharm Des. 2010;16(9):1024-1039.

9. Cederlund A, Gudmundsson GH, Agerberth B. Antimicrobial peptides important in innate immunity. FEBS J. 2011;278(20):3942-3951.

10. Pazgier M, Li X, Lu W, et al. Human defensins: synthesis and structural properties. Curr Pharm Des. 2007;13(30):3096-3118.

11. Yoshio H, Tollin M, Gudmundsson GH, et al. Antimicrobial polypeptides of human vernixcaseosa and amniotic fluid: implications for newborn innate defense. Pediatr Res. 2003;53(2):211-216.

12. Kieffer AE, Goumon $\mathrm{Y}$, Ruh $\mathrm{O}$, et al. The $\mathrm{N}$ - and $\mathrm{C}$-terminal fragments of ubiquitin are important for the antimicrobial activities. FASEB $J$ 2003;17(6):776-778.

13. Harder J, Gläser R, Schröder JM. Human antimicrobial proteins effectors of innate immunity. $J$ Endotoxin Res. 2007;13(6):317-338.

14. Kawasaki H, Iwamuro S. Potential roles of histones in host defense as antimicrobial agents. Infect Disord Drug Targets. 2008;8(3):195-205.

15. McGuckin MA, Eri R, Simms LA, et al. Intestinal barrier dysfunction in inflammatory bowel diseases. Inflamm Bowel Dis. 2009;15(1):100-113. 
16. Larsson JM, Karlsson H, Sjövall H, et al. A complex, but uniform O-glycosylation of the human MUC2 mucin from colonic biopsies analyzed by nanoLC/MSn. Glycobiology. 2009;19(7):756-766.

17. Pearson JP, Brownlee IA. The interaction of large bowel microflora with the colonic mucus barrier. Int J Inflam. 2010;2010:321426.

18. Corfield AP, Myerscough N, Bradfield N, et al. Colonic mucins in ulcerative colitis: evidence for loss of sulfation. Glycoconj J. 1996;13(5):809-822.

19. Shirazi T, Longman RJ, Corfield AP, et al. Mucins and inflammatory bowel disease. Postgrad Med J. 2000;76(898):473-478.

20. Hayashi T, Ishida T, Motoya S, et al. Mucins and immune reaction to mucins in ulcerative colitis. Digestion. 2001;63 Suppl 1:28-31.

21. Kinnebrew MA, Pamer EG. Innate immune signaling in defense against intestinal microbes. Immunol Rev. 2012;245(1):113-131.

22. Rath HC, Herfarth HH, Ikeda JS, et al. Normal luminal bacteria, especially Bacteroides species, mediate chronic colitis, gastritis, and arthritis in HLA-B27/human beta2 microglobulin transgenic rats. J Clin Invest. 1996;98(4):945-953.

23. Sellon RK, Tonkonogy S, Schultz M, et al. Resident enteric bacteria are necessary for development of spontaneous colitis and immune system activation in interleukin-10-deficient mice. Infect Immun. 1998;66(11):5224-5231.
24. Eckburg PB, Relman DA. The role of microbes in Crohn' disease. Clin Infect Dis. 2007;44(2):256-262.

25. Lidar M, Langevitz $\mathrm{P}$, Shoenfeld $\mathrm{Y}$. The role of infection in inflammatory bowel disease: initiation, exacerbation and protection. Isr Med Assoc J. 2009;11(9):558-563.

26. Wehkamp J, Schmid M, Fellermann K, et al. Defensin deficiency, intestinal microbes, and the clinical phenotypes of Crohn's disease. $J$ Leukoc Biol. 2005;77(4):460-465.

27. Kuballa P, Huett A, Rioux JD, et al. Impaired autophagy of an intracellular pathogen induced by a Crohn's disease associated ATG16L1 v a r i a n t . PLoS One. 2008;3(10):e3391.

28. Shih DQ, Targan SR. Insights into IBD Pathogenesis. Curr Gastroenterol Rep. 2009;11(6):473-480.

29. Noda T, Yoshimori T. Molecular basis of canonical and bactericidal autophagy. Int Immunol. 2009;21(11):1199-1204.

30. Hampe J, Franke A, Rosenstiel P, et al. A genome-wide association scan of nonsynonymous SNPs identifies a susceptibility variant for Crohn disease in ATG16L1. Nat Genet. 2007;39(2):207-211.

31. Antoni L, Nuding S, Wehkamp J, et al. Intestinal barrier in inflammatory bowel disease. World J Gastroenterol. 2014;20(5):1165-1179. 